\title{
Establishing Human Resources Strategies and Policies Correlating with Company's Objectives
}

\author{
Prof. Dr. Ion Criveanu ${ }^{1}$, Dr. Ec. Loredana Iordache ${ }^{2}$
}

\begin{abstract}
:
The accent which Romanian companies put during the last period on human resources development had determined the changing of perception way to this organizations' component. For realizing their objectives, companies have to resist to some challenges which request capacity of ensuring and maintaining competition success through anticipating contextual evolutions.
\end{abstract}

Key Words: Human resources strategies, company's objectives.

\footnotetext{
${ }^{1}$ Prof. University of Craiova, Department of Management, ion_criveanu@yahoo.com

${ }^{2}$ Doctor, University of Craiova, Department of Management
} 


\section{Introduction}

Human resources strategy is more and more spoken in Romanian companies. It was often used like an usually term, entering in the terminology of human resources domain without being properly understand. We can't speak about human resources strategy without being available to set a strategy at organizational level. More than this, we can't create and implement a human resources strategy if we don't know mechanisms and components of human resources strategies.

Although there are a series of definitions given to human resources strategies, the scope of their conception and applying must be the same: more and more efficiently using of human resources for realizing company's objectives.

In this context, conception and implementation of human resources strategy do not have to be realized as an isolated event, without continuity, and it must be harmonized with strategic components of the company, with the demands imposed by specific business environment of the company, and also with internal demands of this.

Another aspect which must be taken into account in elaborating human resources strategies is consisting by motivations, demands and comportments of actual employees, which are permanently changing. From this reason, human resources strategy must correlate these needs with company's objectives.

\section{The Rationale}

In the 60 's, using the "strategy term" begun to be used in economy to define ones of the most important decisions of companies. Starting with the 80's, all or almost all became strategic in economy, sociology and psychology, etc. Even it is about groups or individuals' comportment, or economic options, more authors started to think in strategic terms (Břečková and Havlíček, 2013; Havlíček, et al., 2013).

The "strategy" term received different meanings, lengthways time, depending on the domain in which it was used. In human resources domain, in some authors' opinion, strategies express the fact that human or personal resources function is adopting a bigger perspective and a more dynamic vision through human resources, insuring their integration with the other organization's resources.

Other authors had lighted the fact that thinking in human resources strategic terms proves the superannuated anterior conceptions of enterprises which aren't preoccupied about concrete application of important decisions, just them considered strategic: an initial and planned version of strategy idea is criticized and renewed in participative management's perspective and strategic administration of human resources. It is spoken about realizing some links between decisions and their 
application, and so about different actors' associating at strategic level. This widens and partnership version of strategy is ruling today.

From another point of view it is considered that human resources strategy represents the ensemble of activities linked by planning, recruitment, integrating, perfecting, evaluating and motivating human resources. From this widen approach could appear derivate human resources strategies, which make reference just to a part of these activities, like: personnel ensuring, employees' development, the reward, relationships with the employees.

Not taking into account the domains in which human resources strategies can be developed, these must be conceived for being in concordance with company's general objectives. At its turn, company's global strategy has to analyze the field of open possibilities of human resources strategy, and to fructify these possibilities.

The majority of authors consider that in any organization, indifferently of activity's nature, there are two types of objectives:

- $\quad$ strategic objectives on long term which regard a series of aspects contained by human resources strategies' definitions themselves;

- operational objectives, tactical and administrative which suppose activities regarding daily management of work groups.

Long term strategies have a series of objectives which regard aspects of human resources, like:

- satisfying human resources organization's necessarily for the next 5 years, as employees number and also as personnel categories;

- maintaining wages and rewards at a sufficient high level for recruiting, keeping and motivating employees at all organization's levels;

- realizing some harmonious relations between managers and the ones which are in their responsibility;

- ensuring necessarily ways and endowments for maintaining and perfecting labor force's knowledge's and competence;

- $\quad$ ensuring a properly communication system between management and other employees, and also between different organization's departments and functions;

- $\quad$ ensuring necessarily mechanisms for permitting to the organization to stand up in face of human consequences of change.

Analyzing those objectives, we can remark a series of aspects referring to the fact that those are more qualitative and hard quantifying. Although, these objectives are knitting ones with the others, and attainment of ones offers the possibility of quantification through others viewpoint. In another words, we can measure the way 
in which personnel necessarily is satisfied, from the viewpoint of wages offered by the company.

More exactly, competitive wages, professional work frame ensure a low fluctuation and put into attention a high grade of employees' satisfaction. This leads to a stabile work frame, a good image of firm from external, which will determine the possibility of ensuring further human resources necessarily.

Practical, attainment of objectives linked to salaries and motivation strategy also leads to realizing objectives linked to human resources necessarily. Global organization's strategy influents in a main way the strategies form human resources area. Not for a few times, it was established the impossibility of realizing some profitable projects for organization, because company's management was excessively focused on financial and technical aspects, not taking into account human part. Unfortunately, there still is an important part of managers which still consider people like a machine which can be anyway and in any conditions used.

The experience had demonstrated that this thing was especially changed during the last years (Thalassinos and Pociovalisteanu, 2009). Sometimes, people can put up to change, especially when the stress level which they are confronting is important. Sometimes, they aren't enough motivated for doing the necessarily effort to adapt at the new demands, or they do not understand which are new demands, being kept in the past and in old demands which they had realized.

Elaborating human resources strategy must be realized in concordance with company's objectives and it must offer human support for their attainment. There is a series of factors which must be taken into account in elaborating human resources strategy:

- analyzing existent human resources of the organization;

- analyzing internal and external environment;

- knowing general strategy of the company;

- implementing personnel procedures and policies.

The influence of these factors leads to the conclusion that elaborating human resources strategy in an continue process of analysis and diagnosing, and during this process it must be permanently followed in which measure established objectives in human resources area correspond or they are actual to attainment general company's objectives.

Managers have an important role in strategy elaborating, and they have the responsibility of its creation, and also have the role to persuade employees to involve in these strategies' sustaining. The content of human resources strategies must reflect also the content of human resources management or theirs activities, and also the manifestation intensity of the others firm's functions linked by personnel. 
The absence of organizational level of some coherent human resources strategies, makes impossible organizations' adapting at international frame's changes, human resources activities having to be understand in interdependence with all the other process spread at the level of one organization. Management of human resources, as strategic managerial process, is more difficult, comparing with technical progress promotion or financial resources flaw. Organizations which had teaches how to lead their people, applying a performing management of human resources, had passed a step in face of others, because ensuring maintaining human resources' quality are durable strategic processes.

Elaborating a human resources strategy involves elaborating some strategies on each activity on company's functions of human resources, in a smaller or bigger measure, depending of organization's life period. In an organization founded in the "born" period, it will be granting a bigger importance to the recruiting and selecting strategy, reporting with strategic planning of the personnel, for example, whom importance will be putted into evidence in the firm "growth".

Although in specialized literature there are a series of approaches referring to human resources strategies' elaborating, in practice had been often formulated the following strategies:

1. Strategic planning of personnel is difficult to be realized on long term in actual economic conditions, characterized through a high instability and a rapid change of market's conditions. Companies are preoccupied by solving moment problems, and they do not have necessarily capacity for a longer term planning of human resources. Although, we do not have to neglect the fact that company's objectives constitute the start point of any human resources prognosis. Although when we speak in practice about human resources prognosis we generally think to recruitment, especially in growing and maturity phases, we do not have to neglect the aspects linked to available resources' analysis. Making a personnel inventory on professions, preparing, performance it maybe is more advantageous to use personnel form your own company, than to recruit external personnel.

2. Elaborating recruiting, selecting and integrating human resources strategy is the most difficult attribute of managers, in actual conditions. A recruiting and selecting strategy depends on a lot of many internal and external factors. First of all, knowing organization's objectives is very important. Next, are necessarily a series of researches of the following aspects: free posts can be occupied with existent personnel, or through recruitment; there are personnel's record well done, with the attributes of free posts; there is a certain evidence of passes, for recruitment necessarily determination; the free post's attributes can be redistributed.

All these analyses lead to elaborating recruitment strategy, which, as we had mentioned, depends on a series of external factors, like: company's image, demand 
and supply on labor force market, etc. Integration's purpose is the one of facilitating new employee accommodation with work's demands. The group demands aren't every time likewise the manager shows to the new employee. For this, there are many cases in which the new employee can't accommodate itself at work place.

1. Elaborating personnel motivation strategy. Specialized literature discussed a lot the problems about personnel motivation. In practice, these things are harder to be realized, because founding the most adequate strategy of motivating human resources supposes to know very well employees' necessities and demands, which must be corroborated with realizing organization's objectives. Unfortunately, there still is the mentality of a lot of managers that, if people are unsatisfied, they go and we can find others. Things had change a lot in the last 3 years. For that, together with the recruitment, managers have to find solutions for motivating and keeping prepared people. The practice shows us that employees maintaining is as difficult as their selection, but more expensive.

2. Strategies' elaborating regarding rewards system must take into account actual legislative frame-work, and also realizing a performing and motivating system, referring here not just at salary, but also at indirect rewards system, which, in the last years, is more and more important. We can't say that we have exhausted the area of all human resources strategies. Each of these strategies can generate others, and all of them are strongly linked one with another. But, it is necessarily a new approach regarding the ensemble human resources function, referring to constructing some concrete polices and procedures for these strategies sustaining.

While human resources strategies express the ways of objectives attainment in a straighten future inhuman resources area, personnel policies have a smaller horizon, with a stronger measure of detailing and an operational character, their role being the one of sustaining human resources strategies in each of main areas of human resources management.

Establishing a concrete policy in human resources area must take into account personnel importance in a company, responsibility which devolves to the managers, strategic objectives of the organization. A correct formulated personnel policy is the essential element in performance obtaining.

For human resources area's policies attainments their objectives, they must fulfill a series of demands:

- to be clear formulated, redacted and written communicated to all the employees, for not letting place of interpretations;

- to cover all activity domains of the human resources function, especially where the company had proposed strategies on this domain;

- to be consequent and to obtain the whole personnel's adhesion; 
- to be transparent and to allure a bigger number of employees at it's conception and at it's transposing in practice, and so to act at all levels;

- to be in concordance with general objectives and strategies of the company

- to stimulate at each employee the desire of continue improving of his own activity.

In various situations, there are implicitly personnel policies, as a attitude of managers to their subordinated, and as an organization's philosophy expressed through the way in which are approached personnel problems or through the manner in which they treat their employees.

Personnel's policies depend of organization's basal values and they are putting their stamp through organizational culture. Although big majority of managers affirm that in their companies exist human resources policies, a careful analysis shows that a big part of them do not know to describe the nature and content of these policies. The reason is very simple: managers' aware human resources policies' importance, and they want their elaboration only when crises' moments appear into organizations.

For this, elaboration and implementation of human resources policies can't be realized without passing some steps:

- picking up and analyzing some information received from employees and also from managers regarding elaboration of some personnel policies very efficient;

- the analysis of external organization factors, firstly referring here at legislative frame;

- knowing general organization strategies and human resources strategies, regarding the elaboration of some individual human resources strategies on each area of human resources management;

- $\quad$ knowing imparted and accepted organizational values and culture.

After elaborating and accepting human resources policy, this has to be communicated to all employees, an important role devolving to those persons who are putting it in practice.

Applying human resources policy also involves the supervising exerted by human resources managers, and also collaboration with the other departments' managers. The efficiency of elaborating and implementation human resources policy can be verified through the following three ways:

- the way in which human resource policy facilities or not attainment proposed objectives;

- the measure in which this is or isn't compatible with organizational values or culture of the company; 
- the measure in which actual legislation is respected.

\section{Conclusions}

Analyzing the aspects linked to human resources policies, we consider that there aren't recipes in their elaboration and implementation. Each company has its own characteristics, and human resources managers devolve the obligation of founding the best methods for correlating company's objectives with the employees' desires and expectations.

More and more companies understand and try to obtain advantages, as a sequel of applying some coherent human resources policies. Awarding the necessity of human resources strategies and policies does not suppose just strictly specialists intervention in this area, but it also includes an awarding at global level and at each individual level.

Attributing the role of strategic partner in the business internationalizing actual context represents the recognizing of the human resources functions' role and importance, without organization's development weren't possible.

\section{References}

Břečková, P. and Havlíček, K. (2013). Leaders Management and Personnel Controlling in SMEs. European Research Studies Journal, 16 (4), Special Issue on SMEs.

Cole, A.G. 2000, „Personnel's Management ”, Ed CODECS, Bucharest.

Gazier, B. 2003, "Human resources strategies", Ed. Institutul European , Bucharest.

Havlíček, K., Thalassinos I.E. and Berezkinova, L. (2013). Innovation Management and Controlling in SMEs. European Research Studies Journal, 16(4), 57-70, Special Issue on SMEs.

Lefter, V., Diaconu, A., Marinas, C. and Puia, R. 2008, - Human Resources Management, Ed. Economica, Bucharest.

Manolescu, A. 2003, "Human Resources Management”, Ed. Economica, Bucharest.

Thalassinos, I.E. and Pociovalisteanu, M-D. (2009). The Structural Funds and the Economic and Social Cohesion Process. Annals-Economy Series 1, 313-330. 